\title{
Nuclear Magnetic Resonance Studies of Erythrocyte Membranes
}

\author{
D. Chapman, V. B. Kamat, J. de Giert and S. A. Penkett \\ Molecular Biophysics Unit, Unilever Research Laboratory \\ The Frythe, Welwyn, Herts., England
}

(Received 8 May 1967, and in revised form 7 September 1967)

\begin{abstract}
The use of nuclear magnetic resonance spectroscopy for studying molecular interactions in biological membranes has been investigated using erythrocyte membrane fragments. Sonic dispersion of these fragments produces a sharp and well-defined high-resolution nuclear magnetic resonence spectrum. The spectrum shows peaks which can be assigned to various groups of the lipid, sugar and protein. The choline $\mathrm{N}^{+}\left(\mathrm{CH}_{3}\right)_{3}$ signal of the membrane lipid is prominent but the signal due to $\left(\mathrm{CH}_{2}\right)_{n}$ protons of the hydrocarbon chains is broadened as a result of interaction. This signal narrows at higher temperatures or when exposed to increasing concentrations of sodium deoxycholate.

Signals due to amino acids of the membrane protein are unresolved in the spectrum but appear as well-defined peaks after treatment with urea or trifluoroacetic acid. Co-dispersion of the membrane fragments with lysolecithin gives a spectrum which indicates the formation of an additive complex.
\end{abstract}

\section{Introduction}

Previous studies from this laboratory have shown that nuclear magnetic resonance spectroscopy provides useful information about phospholipids in organic solution (Chapman \& Morrison, 1966), the nature of their bulk mesomorphic behaviour (Chapman \& Salsbury, 1966) and their interaction with cholesterol (Chapman \& Penkett, 1966). These studies have encouraged us to apply this technique to natural membrane systems. In a preliminary note (Chapman, Kamat, de Gier \& Penkett, 1967), we demonstrated that high-resolution proton magnetic resonance spectra can be obtained with aqueous dispersions of erythrocyte membrane fragments. Here we report additional evidence for these spectral assignments, and discuss the spectral changes produced by temperature, by protein denaturants and also the interaction of the membrane fragments with sodium deoxycholate and lysolecithin.

\section{Experimental Procedure}

(a) Preparation of erythrocyte ghost fragments and lipid extracts

Erythrocyte ghosts were prepared according to the method of Dodge, Mitchell \& Hanahan (1963) with minor modifications. Two to 3 woeks old human erythrocytes (group A, Rh positive), preserved in acid-citrate doxtrose at 0 to $4^{\circ} \mathrm{C}$, were washed once with saline, 4 times with 310 ideal milliosmolar phosphate buffer $\mathrm{pH} \mathbf{7 . 4}$ and were haemolysed with 20 vol. of 20 ideal milliosmolar phosphate buffer $\mathrm{pH} 7 \cdot 4$. Ghosts were recovered

$\dagger$ Visiting scientist from the Department of Biochemistry, State University of Utrecht, The Netherlends. 
from the haemolysate by centrifugation at $18,000 \mathrm{rev} . / \mathrm{min}$ for $5 \mathrm{~min}$ in rotor no. 19 in the Spinco Preparative Ultracentrifuge L2-50. These were washed 3 times ; with 20

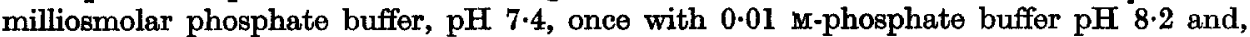
finally, with $0.001 \mathrm{M}$-phosphate buffer $\mathrm{pH}$ 8. The ghost fragments thus obtained were further desalted by dialysis against at least 300 vol. of ice-cold distilled and deionized water overnight and freeze-dried. The final product was pearly white to very pale pinkish in colour, and was stored at $-15^{\circ} \mathrm{C}$ in a desiccator over silica gel.

Haemoglobin estimated in the final product by the pyridine-haemochromogen method of Rimington (1942) was less than $0.5 \%$ of the total protein $(<0.24 \%$ of freeze-dried weight) of the membrane.

Protein was determined by the method of Lowry, Rosebrough, Farr \& Randall (1951) using crystalline bovine serum albumin as a reference standard, and accounted for 47 to $52 \%$ of the freeze-dried material.

Total lipid was extracted from the freeze-dried material by the procedure of Reed, Swisher, Marinetti \& Eden (1960). It constituted 38 to $42 \%$.

Lipid phosphorus was estimated by the method of Lowry, Roberts, Leiner, Wu \& Farr (1954).

Phosphotipid was separated from the neutral lipid by silicic acid chromatography (Borgström, 1952).

Cholesterol was determined on the lipid extract by the procedure of Abell, Levy, Brodie $\&$ Kendall (1952). The molar ratio of cholesterol to phospholipid was of the order of 0.85 to 0.88 .

Lipid-deficient membrane, free of all the neutral lipid and $25 \%$ of phospholipid was prepared by ether extraction of freeze-dried membrane by the method of Roelofsen, de Gier \& van Deenen (1964).

\section{(b) Treatment of the membrane fragments with enzymes}

(i) Phospholipase $C .50 \mathrm{mg}$ of freeze-dried material was resuspended in $5 \mathrm{ml}$. of Tris buffer $0.05 \mathrm{M}, \mathrm{pH} 7.4$ containing $5 \mathrm{~m}$-moles $\mathrm{Ca}^{2+}$ ions and $2 \mathrm{mg} / \mathrm{ml}$. of phospholipase $\mathrm{C}$ (from Clostridium welchii, Sigma Chemicals). The suspension was incubated at $37 \cdot 5^{\circ} \mathrm{C}$ for $1 \mathrm{hr}$. It was spun at $39,000 \mathrm{rev} . / \mathrm{min}$. for $10 \mathrm{~min}$. The pellet was washed once with distilled water, twice with phosphate buffer $(0.310 \mathrm{M}, \mathrm{pH} 7 \cdot 4)$ and finally with $\mathrm{D}_{2} \mathrm{O}(99.7 \%)$.

(ii) Neuraminidase. $50 \mathrm{mg}$ of the freeze-dried membrane was resuspended in $0.01 \mathrm{M}$ acetate buffer, $\mathrm{pH} 5.4$, containing $5 \mathrm{~mm}-\mathrm{Ca}^{2+}, 0.05 \mathrm{M}-\mathrm{NaCl}$ and $0.5 \mathrm{mg} / \mathrm{ml}$. of crystalline neuraminidase (Clostridium perifringens, Sigma Chemicals). It was incubated at $37 \cdot 5^{\circ} \mathrm{C}$ for $1 \mathrm{hr}$ and was spun at $39,000 \mathrm{rev} . / \mathrm{min}$ for $10 \mathrm{~min}$. The supernatent solution was assayed for the release of sialic acid by Warren's method (1959). About $2 \cdot 3 \mu$ moles of sialic acid/ $50 \mathrm{mg}$ of the freeze-dried material (equivalent to 0.34 to $0.36 \mu \mathrm{mole} / \mathrm{ml}$. of packed cells) were released by this treatment. Control incubation tubes containing heat-inactivated $\left(100^{\circ} \mathrm{C}\right.$ for $3 \mathrm{~min}$ ) enzyme did not release sialic acid. Both the pellets were washed twice with distilled water, twice with $0.310 \mathrm{M}$-phosphate buffer $\mathrm{pH} \mathbf{7 \cdot 4}$ and twice with $\mathbf{9 9 \cdot 7 \%}$ $\mathrm{D}_{2} \mathrm{O}$.

\section{(c) Nuclear magnetic resonance spectroscopy}

The high-resolution proton magnetic resonance spectra were recorded on "a PerkinElmer R10 spectrometer which operates at $60 \mathrm{Mc} / \mathrm{s}$. Chemical shifts $\tau$ are expressed in parts per million relative to tetramethyl silane at 10 p.p.m. Unless otherwise specified, the samples were placed in the spectrometer at $33.4^{\circ} \mathrm{C}$. The spectra were printed out after a number of accumulations varying from 64 to 512 using a C.a.t. (computer of average transients-Northern Scientific N.S. 544, digital memory oscilloscope). The number of scans was determined in each case by an adequate signal/noise ratio, which is proportional to the square root of the accumulations.

(i) Erythrocyte ghosts and fragments. $50 \mathrm{mg}$ of freeze-dried membrane or its equivalent amount of ghosts (usually derived from 3 to $5 \mathrm{ml}$. packed erythrocytes) were spun at $20,000 \mathrm{~g}$ for $45 \mathrm{~min}$ in a Spinco $\mathrm{SW39}$ rotor. They were washed twice with 20 milliosmolar phosphate buffer $\mathrm{pH} \mathrm{7.4} \mathrm{in} 99.7 \% \mathrm{D}_{2} \mathrm{O}$. The final pellets were resuspended in $1 \mathrm{ml}$. of the buffer and examined in the spectrometer before and after sonication. Sonic dispersion was carried out with a soniprobe (Dawe Instruments Ltd.) at $20 \mathrm{kc} / \mathrm{s}$ between 3 and 5 min 
with the sample placed in a Lusteroid tube surrounded by ice-cold water. The temperature of the sumple did not exceed $20^{\circ} \mathrm{C}$. Under these conditions turbidity of the mermbrane suspension was reduced by about $50 \%$. About one-third of the sonicated membrane material, as measured by lipid phosphorus and protein on the supernatant fraction, was sodimontablo at $20,000 \mathrm{~g}$ for $45 \mathrm{~min}$. Over $75 \%$ of the material becamo sodimentable at $105,000 \mathrm{~g}$ in $60 \mathrm{~min}$ in the form of a translucent pellet.

(ii) Temperature run. A $5 \%$ sonic dispersion of the freeze-dried membrane in $99 \cdot 7 \% \mathrm{D}_{2} \mathrm{O}$ was examined at $10,20,30,40,50,60,80,100,120$ and $150^{\circ} \mathrm{C}$ in the spectrometer, with a variable temperature probe.

(iii) Ox brain ganglioside (a gift from Dr Gammack) and neuraminic acid (Sigma Chemicals) were dissolved in $\mathrm{D}_{2} \mathrm{O}$ and examined in the spectrometer. These were used as reference compounds to aid assignments of various signals in the membrane spectra.

(iv) Enzyme-treated membrane fragments were dispersed in $99 \cdot 7 \% \mathrm{D}_{2} \mathrm{O}$ to make a $5 \%$ dispersion.

(v) Total lipid, phospholipid and lipid-deficient (ether extracted) membrane fragments were freed of traces of organic solvents under vacuum on a rotary evaporator and dispersed in $99 \cdot 7 \% \mathrm{D}_{2} \mathrm{O}$ to represent equivalents of a $5 \%$ dispersion of the starting material.

(vi) Effect of protein denaturants. Freeze-dried membrane fragments were co-dispersed with $8 \mathrm{M}$-urea in $\mathrm{D}_{2} \mathrm{O}$ or dissolved in trifluoroncetic acid.

(vii) Effect of sodium deoxycholate and lysolecithin. 5\% co-dispersions of freozo-driod membrane fragments were examined in the presence of varying concentrations of sodium deoxycholate or lysolecithin (Koch Light Laboratories).

\section{Results}

Spectra obtained with intact ghosts in 20 milliosmolar phosphate buffer $\mathrm{pH} 7 \cdot 4$ in $\mathrm{D}_{2} \mathrm{O}$ or with homogenized ghost fragments were weak and variable in intensity, whereas ultrasound dispersions gave consistent and reproducible spectra.

\section{(a) Spectral assignments and temperature effects}

The high-resolution proton magnetic resonance spectra of deuterium oxide dispersions of the freeze-dried membrane, recorded at various temperatures, are shown in Fig. 1. No high-resolution signals are observable at 10 and $20^{\circ} \mathrm{C}$. Spectra are obtained at $30^{\circ} \mathrm{C}$ and higher tomperaturcs. Signals observed between 30 and $40^{\circ} \mathrm{C}$ occur at 6.3 p.p.m., 6.7 p.p.m., 7.8 p.p.m., 8.7 p.p.m. and 9.1 p.p.m. Making use of n.m.r. correlation tables (Chapman \& Magnus, 1966) and the spectra of related molecules, we assign the peaks.

The presence of phospholipids, such as diacylphosphatidylcholine and sphingolipid, in the material (van Deenen \& de Gier, 1964) suggests that the signal at 6.7 p.p.m. is associated with the protons of the choline group $\mathrm{N}^{+}\left(\mathrm{CH}_{3}\right)_{3}$. A signal at this position is observed with o-phosphocholine chloride $\mathrm{Ca}^{2+}$ salt when it is dissolved in $\mathrm{D}_{2} \mathrm{O}$ (Chapman \& Morrison, 1966) and with pure model phospholipids. Furthermore, the spectrum of the membrane fragments treated with phospholipase C (Fig. 2) shows that the peak at 6.7 p.p.m. has been removed. There is also an increase in the intensity of $\left(\mathrm{CH}_{2}\right)_{n}$ peak at 8.7 p.p.m. This enzyme is known to catalyse hydrolysis of diglyceride phosphate linkages in lecithin and other phospholipids (Macfarlan \& Knight, 1941; de Gier, de Haas \& van Deenen, 1961). In the spectrum of the untreated membrane no signals are apparent at 4.7 p.p.m. due to the unsaturated $\mathrm{CH}=\mathrm{CH}$ groups which are present in the hydrocarbon chains of the lipid. Moreover, the signal at 8.7 p.p.m. in the region expected for the $\mathrm{CH}_{2}$ protons of the alkyl chains is extremely weak compared with the situation observed with a phospholipid dissolved in an 


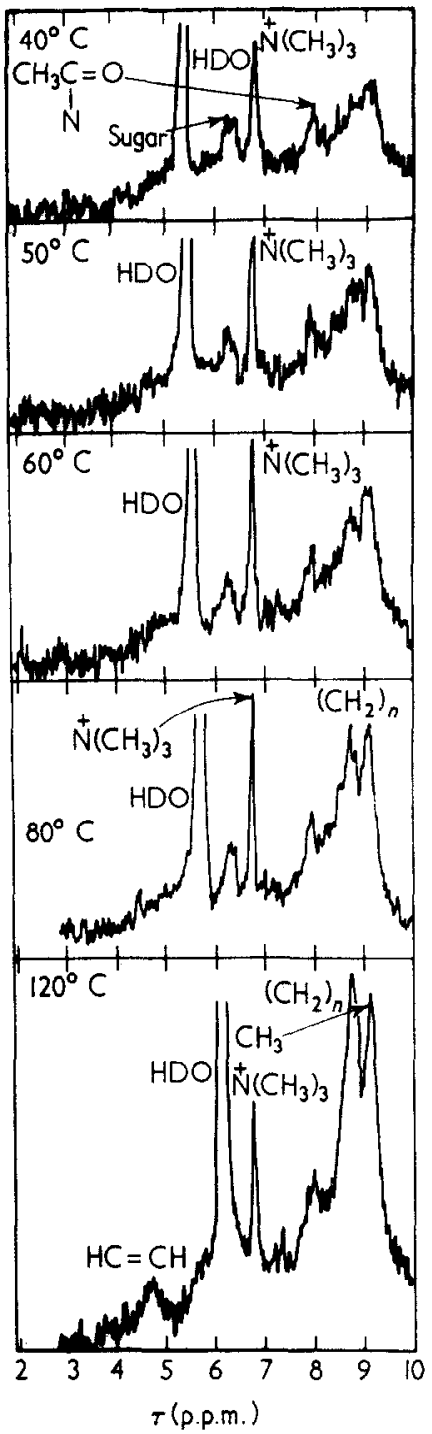

Fig. 1. The p.m.r. spectra at different temperatures of a sonicated dispersion $(5 \% \mathrm{w} / \mathrm{v})$ of erythrocyte membrane fragments in $\mathrm{D}_{2} \mathrm{O}$ (64 scans).

organic solvent (Chapman \& Morrison, 1966), or when it is dispersed in water (Chapman \& Penkett, 1966). A peak in the spectrum at $9 \cdot 1$ p.p.m. can be assigned to methyl $\left(\mathrm{CH}_{3}\right)$ protons of the lipid, cholesterol, or to the protein of the membrane. The high resolution p.m.r. spectrum of cholesterol dissolved in an organic solvent shows peaks in this region (Chapman, 1965) and proteins dissolved in $\mathrm{D}_{2} \mathrm{O}$ show absorption in this region (Kowalsky, 1962).

The assignments of the remaining signals are not so straightforward. Carbohydrates such as $N$-acetyl-glucosamine, $N$-acetyl-galactosamine and $N$-acetylneuraminic acid are localized at the surface of erythrocyte membranes (Cook, 1962; Eylar, Madoff, Brody \& Oncley, 1962; Watkins, 1966). This suggests that some of 
these p.m.r. signals may originate from protons in these sugar residues. The highresolution p.m.r. spectra of ox-brain ganglioside and $N$-acetyl-neuraminic acid (Fig. 3) and of related molecules like $N$-acetyl-neuramine lactose and $N$-acetylglucosamine (unpublished observation) also show peaks in the same positions as those which occur in the spectra of the erythrocyte membrane. On the basis of these reference spectra and the use of correlation tables, the peak at 7.8 p.p.m. is therefore

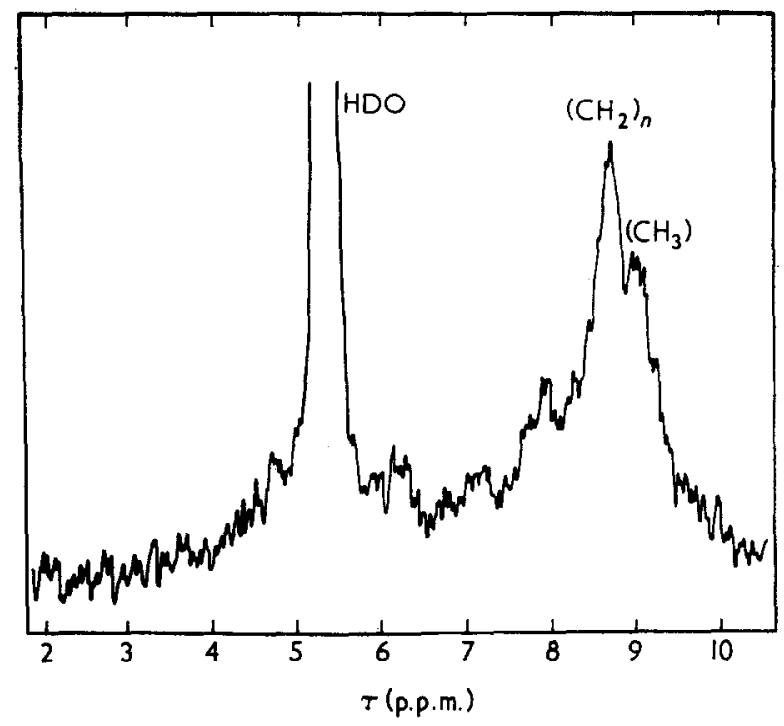

Fra. 2. The p.m.r. spectrum of erythrocyte membrane fragments pretreated with phospholipase $\mathrm{C}$ and sonicated in $\mathrm{D}_{2} \mathrm{O}$ to form a $5 \%$ dispersion ( 512 scans).

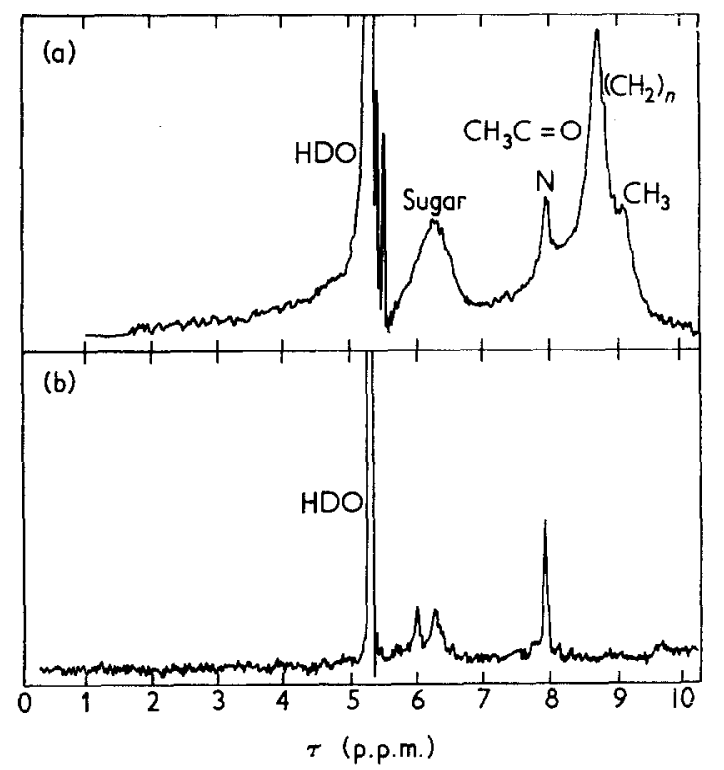

FIG. 3. The p.m.r. spectrum of (a) ox-brain ganglioside ( $3 \%$ ) (64 scans); (b) $N$-acetyI neuraminic acid in $\mathrm{D}_{2} \mathrm{O}(2 \%)$. 
tentatively assigned to $N$-acetyl protons $\left(\mathrm{NCOCH}_{3}\right)$. Quantitative removal of sialic acid (Wallach \& Kamat, 1966) from the membrane fragments, however, did not significantly reduce the $\mathrm{NCOCH}_{3}$ proton signal at 7.8 p.p.m. indicating a cumulative contribution from $N$-acetyl sugar residues and $\mathrm{NCOCH}_{3}$ groups possibly from proteins. The signal at 6.3 p.p.m. is considered to arise from protons present in the sugar residues and perhaps to $\mathrm{CH}_{2} \mathrm{OP}$ and $\mathrm{CH}_{2} \mathrm{OCO}$ groups of the lipids.

With increase in temperature, several changes in the p.m.r. spectrum occur. (a) The signal at 6.7 p.p.m. $\left(\mathrm{N}^{+}\left(\mathrm{CH}_{3}\right)_{3}\right)$ becomes sharper and peak height increases. The area of this peak remains approximately constant. (b) The signal at 8.7 p.p.m. assigned to $\left(\mathrm{CH}_{2}\right)_{n}$ protons increases in intensity whilst the peak at $9 \cdot 1$ p.p.m. due to methyl protons becomes sharper. (c) A new peak becomes apparent at 4.7 p.p.m. $(\mathrm{CH}=\mathrm{CH}$ protons $)$. Above $120^{\circ} \mathrm{C}$ the intensities of all signals in the spectrum seem to fall, due probably to thermal breakdown of the membrane. The peak associated with water (at $5 \cdot 2$ p.p.m. at $30^{\circ} \mathrm{C}$ ) shifts to higher $\tau$-values at higher temperatures.

\section{(b) Comparison of lipid and erythrocyte ghost spectra}

In Fig. 4 are shown the p.m.r. spectra of deuterated dispersions of (a) freezedried ghost fragments, (b) the total equivalent lipid (phospholipid + cholesterol), (c) the total equivalent phospholipid, and (d) lipid-deficient, ether-extracted membrane, depleted of all cholesterol and about $25 \%$ of its phospholipid. The assignments of the peaks in the phospholipid spectrum (Fig. 4(c)) follow directly from the p.m.r. studies of phospholipids in organic solvents and were confirmed by integration techniques (Chapman \& Morrison, 1966). The spectrum of the total lipid extract (phospholipid and cholesterol) shows a strong signal at 8.7 p.p.m. associated with $\left(\mathrm{CH}_{2}\right)_{n}$ protons, but the peak at $9 \cdot 1$ p.p.m. when compared with the spectrum of the phospholipid alone, has increased intensity associated with the $\mathrm{CH}_{3}$ protons of cholesterol. The remaining peaks present in the spectrum of the phospholipid, including the peak associated with the $\mathrm{HC}=\mathrm{CH}$ protons, are also present in the total lipid extract. The spectrum of the cholesterol-free erythrocyte membrane is qualitatively not very different from that of the spectrum of the starting material shown in Fig. 4(a).

\section{(c) The effect of protein denaturants on the membrane spectrum}

The spectrum of membrane dispersed in the presence of $8 \mathrm{M}$-urea is shown in Fig. 5(a). It has a weak signal at 2.5 p.p.m. which we assign to a ring hydrogen of histidine and amino and peptide hydrogens by comparison with published p.m.r. spectra of proteins (Kowalsky, 1962). The spectrum contains a $4 \cdot 3$ p.p.m. signal of urea and peaks at $6 \cdot 3$ and $7 \cdot 8$ p.p.m. due to sugar groups and the $\mathrm{CH}_{3}$ proton signal at 9.1 p.p.m. The urea-treated membrane also shows a signal at 6.7 p.p.m. due to $\mathrm{N}^{+}\left(\mathrm{CH}_{3}\right)_{3}$ protons associated with protons in the choline group. A weak signal at 7.2 p.p.m. may be due to methylene protons in the membrane protein where the carbon of the methylene is adjacent to a nitrogen or sulphur atom or to a carboxyl group or an aromatic ring (Kowalsky, 1962).

Results of the membrane fragments in trifluoroacetic acid (Fig. 5(b)) reveal the following features:

(i) A signal at 2 to 2.2 p.p.m. which we assign to histidine and amino peptide hydrogens of the membrane protein. 
(ii) A signal at $2 \cdot 6$ p.p.m. which we assign to ring hydrogens of aromatic amino acids, e.g. phenylalanine of the membrane protein.

(iii) A peak near 4.7 p.p.m. associated with $\mathrm{CH}=\mathrm{CH}$ protons.

(iv) A broad peak assigned to $\alpha$-hydrogens of the amino acids at $5 \cdot 2$ to $5 \cdot 4$ p.p.m.

(v) A peak assigned to choline protons at 6.7 p.p.m.

(vi) Peaks at 6.3 and 7.8 p.p.m. assigned to $\beta$-methylene groups and methionine methyl groups or, alternatively, to weak sugar residue protons.

(vii) A strong peak at 8.7 p.p.m. due to $\left[\mathrm{CH}_{2}\right]_{n}$ protons of the lipid chain.

(viii) A signal at $9 \cdot 1$ p.p.m. to $\mathrm{CH}_{3}$ protons.

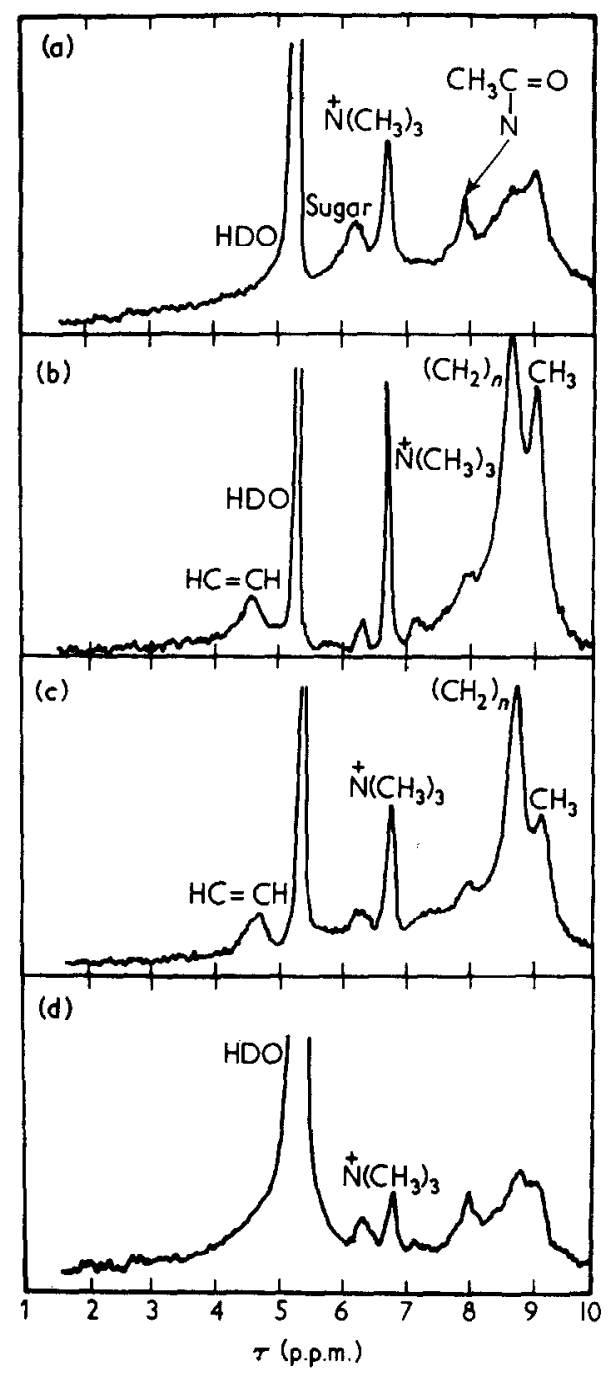

FIg. 4. The p.m.r. spectrum of a $5 \%$ sonicated dispersion in $\mathrm{D}_{2} \mathrm{O}$.

(a) Erythrocyte membrane fragments; (b) total equivalent membrane lipid (phospholipid + cholesterol); (c) total equivalent phospholipid; (d) lipid-deficient membrane fragments extracted with ether to remove all cholesterol and about $25 \%$ phospholipid (64 scans each). 


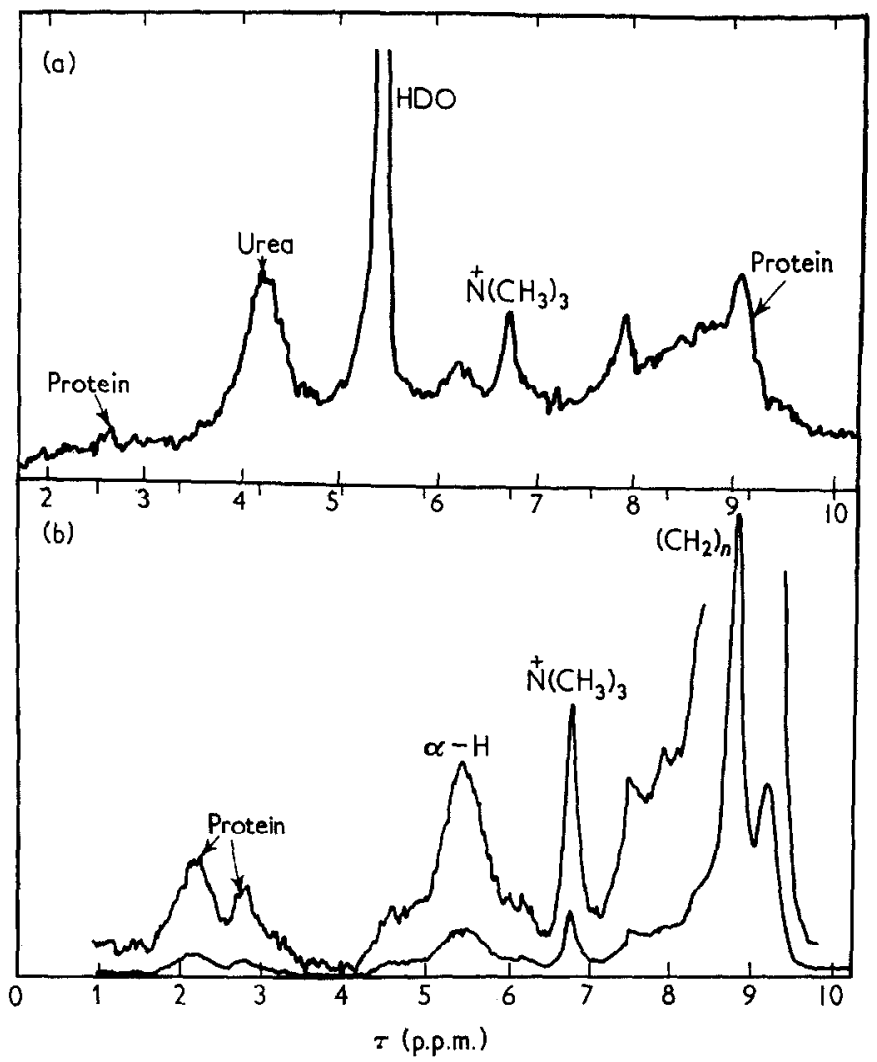

Fig. 5. The p.m.r. spectra of membrane fragments.

(a) Co-dispersed with 8 M-urea; (b) dissolved in trifluoroacetic acid $(2.5 \%$ membrane concentration).

(d) The interaction of sodium deoxycholate and lysolecithin with the membrane fragments

The p.m.r. spectra of erythrocyte ghost fragments examined in the presence of varying concentrations of sodium deoxycholate are shown in Fig. 6. The p.m.r. spectrum of sodium deoxycholate has been reported previously (Chapman et al., 1967).

The p.m.r. spectrum of the membrane fragments at the deoxycholate concentration of 0.25 and $0.5 \mu \mathrm{mole} / \mathrm{mg}$ membrane protein is similar to that of the untreated material (Fig. 4(a)). Exposure to deoxycholate concentrations greater than $1 \mu$ mole/ $\mathrm{mg}$ membrane protein, however, results in an increased intensity of the peak of 8.7 p.p.m. associated with the $\left(\mathrm{CH}_{2}\right)_{n}$ signal of the hydrocarbon chains, and is accompanied by the appearance of a signal at $4 \cdot 7$ p.p.m. due to olefinic $\mathrm{CH}=\mathrm{CH}$ protons of the lipid chains.

The effect of lysolecithin on the p.m.r. spectrum of the membrane fragments is shown in Fig. 7. A comparison of the spectrum of lysolecithin with and without erythrocyte ghost material reveals that the $\left(\mathrm{CH}_{2}\right)_{n}$ signal of lysolecithin at 8.7 p.p.m. is markedly inhibited in the presence of the membrane. The area of the signal 
due to $\mathrm{N}^{+}\left(\mathrm{CH}_{3}\right)_{3}$ protons in the spectrum of ghost plus added lysolecithin is due to additional contributions of the protons from the choline group of the lysolecithin.

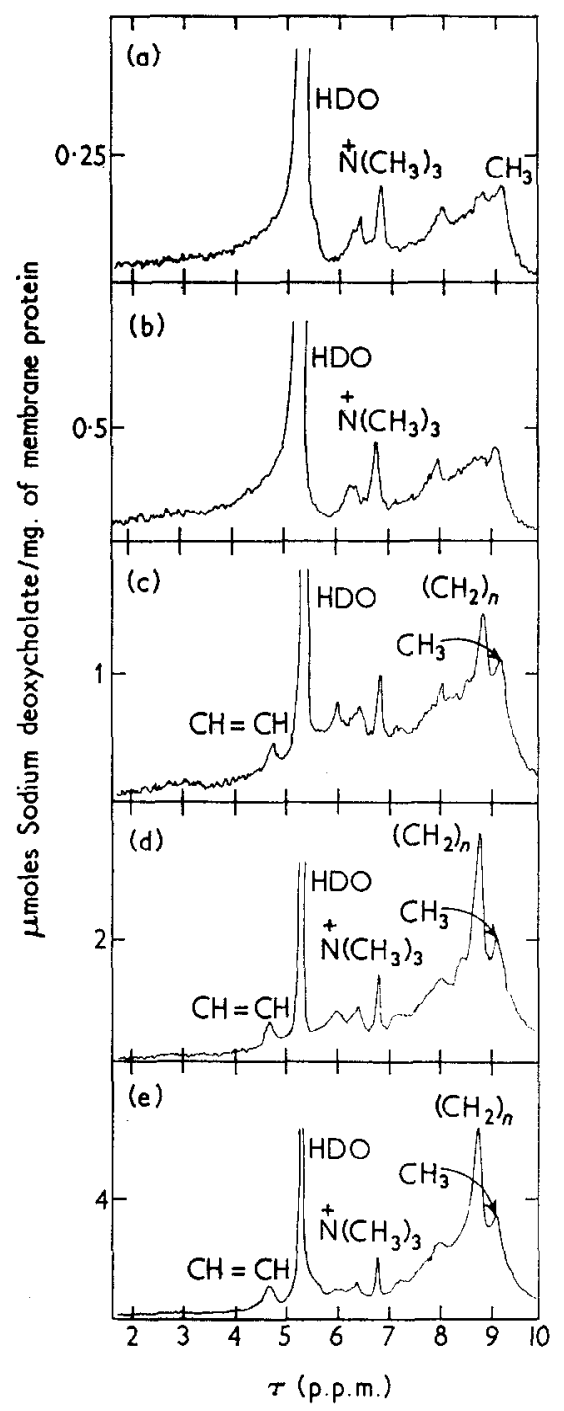

Fia. 6. The p.m.r. spectrum of erythrocyte membrane fragments co-dispersed by sonication in $\mathrm{D}_{2} \mathrm{O}$ at $5 \%(\mathrm{w} / \mathrm{v})$ concentration with increasing concentrations of sodium deoxycholate (64 scans). Spectra in (d) and (e) are printed out at one-half and one-quarter the sensitivity of (a), (b) and (c).

\section{Discussion}

(a) Nuclear magnetic resonance spectroscopy

Proton magnetic resonance line widths in solids, glasses, and viscous liquids are considerably greater than in ordinary liquids and gases. Typical line widths for solids are 1000 to 100,000 times as broad as liquid lines and are undetectable on highresolution spectrometers. This is due to variations in local magnetic fields caused by static neighbouring nuclear magnetic moments. Chemically equivalent protons can have neighbouring magnetic dipoles at different orientations and distances. 


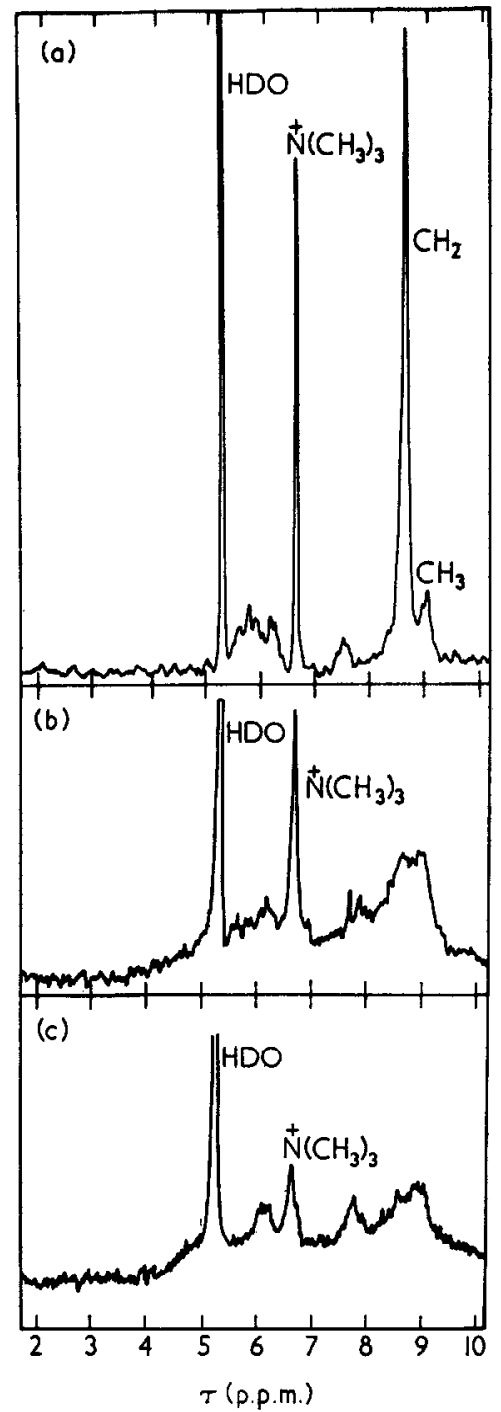

FiG. 7. The p.m.r. spectrum of ultrasound dispersions in $\mathrm{D}_{2} \mathrm{O}$ of (a) lysolecithin (2\%); (b) erythrocyte membrane fragments co-dispersed with $1 \%$ lysolecithin; (c) as in (b) but with $2 \%$ lysolecithin (64 scans).

These variations in local field lead to a line broadening of the order of $10^{5} \mathrm{c} / \mathrm{s}$ for typical hydrogen-containing rigid solids.

In liquids the magnetic moments are in relative motion due to molecular translation and rotation. This motion causes fluctuations of the local field. If the characteristic time $\tau_{c}$ of this motion is short compared with a characteristic time $\tau_{h}$, the individual protons will "see" only the time average local field, which is nearly the same for all chemically equivalent protons. This "motional narrowing" reduces the line widths to a few c/s. The time $\tau_{h}$ is of the order of the reciprocal of the line width (expressed in $\mathrm{c} / \mathrm{s}$ ) of a rigid lattice. Thus the condition for motional narrowing is

$$
\tau_{0} \leqslant 10^{-6} \text { sec. }
$$


If, in the membrane organization, the period of reorientation of any segments of the components is long compared with $10^{-5} \mathrm{sec}$, there will be no high-resolution peaks. If, on the other hand, either over-all rotation of an ordered segment or reorientation within the membrane is rapid compared with this time, typical liquid-like highresolution spectra characteristic of the component units will be observed. If the period of the motion is of the order of $10^{-5} \mathrm{sec}$, an intermediate linewidth will result.

The n.m.r. measurement deals with times of the order of intramolecular rotalion periods rather than times characteristic of optical transitions, and would appear to be an important measurement in terms of most molecular processes. The integrated intensity of a high-resolution sharp peak is, under certain conditions, directly proportional to the number of protons that it represents.

\section{(b) The membrane spectrum}

In line with the preceding discussion, solid phospholipids at liquid-nitrogen temperature give broad n.m.r. lines about 15 Gauss wide $\left(6 \times 10^{4} \mathrm{c} / \mathrm{s}\right)$. In the mesomorphic liquid crystalline condition, the line width falls (Chapman \& Salsbury, 1966) to about $0 \cdot 1$ Gauss $\left(4 \times 10^{2} \mathrm{c} / \mathrm{s}\right)$. A high-resolution n.m.r. spectrum of a phospholipid such as egg-yolk lecithin in water is observed only after ultrasonic dispersion. In this sonicated dispersed state the phospholipid is thought to be present in bilayer form (Bangham, 1963; Saunders, 1966) of very small mesomorphic aggregates. The reason for this increased resolution of the p.m.r. spectra of phospholipids in water after ultrasonication appears to be associated with magnetic inhomogeneity effects which are present with coarse aggregates but are averaged out with the resultant smaller particles (Penkett, Flook \& Chapman, manuscript in the press).

Intact ghosts or homogenates of freeze-dried material give spectra of poorly defined intensities. A well-defined high resolution p.m.r. spectrum of erythrocyte membrane fragments is obtained with sonicated dispersions. Since higher force fields are required to sediment sonicated dispersions of the membrane (see Experimental section), our results indicate that sonic irradiation reduces the membrane fragments to microsomal dimensions. These particles are small enough to allow rapid reorientation, permitting observation of a well-resolved spectrum if the sogmental motion of the membrane components is sufficiently rapid.

Below $20^{\circ} \mathrm{C}$ the membrane spectrum is featureless and unresolved, but sharpens up at $30^{\circ} \mathrm{C}$ and at higher temperatures (Fig. 1). This is characteristic of a system in which there is considerable molecular motion perhaps because of a liquid crystalline arrangement of the lipids and proteins. Studies on the viscosity of blood (Dintenfass, 1964) and X-ray diffraction of an erythrocyte lipid-water system (Rand \& Luzzati, 1967) provide some support for this inference.

The narrow line widths in the membrane spectrum (Fig. 1) may be explained on the basis of the segmental motion for specific proton groupings and are considered to be determined by the local viscosity $\dagger$ in the immediate neighbourhood of the particular chain segment. A similar situation has been observed with the n.m.r. spectra of polymers, e.g. polystyrene in $\mathrm{CCl}_{4}$ (Bovey, Tiers \& Filipovich, 1959). The constant area of the choline peak at higher temperatures, or after the exposure of the membrane fragments to varying concentrations of bile salt, shows that nearly all the choline-containing lipid (lecithin and sphingomyelin) contributes to this peak. Other

† The local viscosity will begin to be affected when neighbouring chain segments restrict each other's motion. 
narrow signals in the membrane spectrum are associated with protons in the sugar residues. In all the prevailing membrane models (Danielli \& Davson, 1935; Robertson, 1960; Lenard \& Singer, 1966), the lipid polar head groups are postulated to be in electrostatic interaction with the polar residues of the protein and are in a hydrated environment. Moreover, the external surface of the erythrocyte membrane has a large number of short oligosaccharide chains covalently attached at intervals to peptide backbone (Watkins, 1966). It is possible that the positional orientations of the polar groups and oligosaccharide may provide regions of sufficiently low microscopic viscosity to permit segmental motion of the choline and sugar protons, viz. $\mathrm{N}\left(\mathrm{CH}_{3}\right)_{3}$, N.CO. $\mathrm{CH}_{3}$ and $\mathrm{CH}_{2} \mathrm{OC}$ or $\mathrm{CH}_{2} \mathrm{OP}$ groups.

The most important feature of the membrane spectrum is the broadening in the region of 8 and 9 p.p.m. The inhibition of the $\left(\mathrm{CH}_{2}\right)_{n}$ signal at 8.7 p.p.m. and the absence of the $\mathrm{CH}=\mathrm{CH}$ signal at $4 \cdot 7$ p.p.m. are most striking, and indicate a high local viscosity for the hydrocarbon lipid chains in the membrane. These peaks are, however, present in the spectra of sonic dispersions of egg-yolk lecithin, but are suppressed in a co-dispersion of egg-yolk lecithin with cholesterol (Chapman \& Penkett, 1966) probably due to sterol-phospholipid interaction. Spectra obtained with aqueous dispersions of red blood cell membrane phospholipid and total lipidcontaining cholesterol (Fig. 4(b) and (c)), however, do not show a similar inhibition of $\left(\mathrm{CH}_{2}\right)_{n}$ and $\mathrm{CH}=\mathrm{CH}$ peaks. Cholesterol-phospholipid interaction therefore does not appear to be a major determinant in the observed broadening in the membrane spectrum between 8 and 9 p.p.m. This is further supported by the spectrum of lipiddeficient membrane where removal of all cholesterol by ether extraction does not cause the $\left(\mathrm{CH}_{2}\right)_{n}$ signal to appear (Fig. $4(\mathrm{~d})$ ).

Our explanation for the inhibition of the $\left(\mathrm{CH}_{2}\right)_{n}$ peak and the appearance of the broad absorption band between 8 and 9 p.p.m. in the membrane spectrum is that it is due to the lipid-protein interaction. It is difficult to imagine that a mere sandwich of a phospholipid bilayer between protein monolayers envisioned by older models (Danielli \& Davson, 1935; Robertson, 1960) could itself cause inhibition of the chain signal. In our interpretation non-polar amino acids of the protein interact with hydrocarbon chains, increase magnetic dipole interactions between adjacent $\mathrm{CH}_{2}$ groups and restrict their segmental motion by raising the local viscosity. Evidence supporting such an interaction is provided by spectra of the membrane treated with protein denaturants.

Previous studies on the n.m.r. spectra of proteins (Bovey et al., 1959; Kowalsky, 1962) have demonstrated that large globular proteins, e.g. bovine serum albumin (mol. wt 65,000) give poorly resolved spectra. A major absorption band occurs at 8.8 p.p.m. with a width of about $100 \mathrm{c} / \mathrm{s}$. In general, however, fine structure is absent. Upon treatment with denaturing agents, e.g. urea or trifluoroacetic acid, peaks become sharper and new peaks appear. Both urea and trifluoroacetic acid are known to disrupt the secondary and tertiary structure of proteins (Hippel \& Wong, 1964; Bovey, Yanari \& Tiers, paper presented at 133rd Meeting of Amer. Chem. Soc., April 1958) and convert them into a random coiled conformation.

The broad absorption band between 8 and 9 p.p.m. in the membrane spectrum may therefore have contributions from the protein, but signals due to individual amino acids are not resolved. Even treatment with urea (Fig. 5(a)) sharpens only the methyl proton signal and gives rise to a small peak due to aromatic amino acids but does not increase the intensity of chain signal at 8.8 p.p.m. Treatment with 
trifluoroacetic acid, however, gives an n.m.r. spectrum containing many signals (Fig. 5(b)). Many new peaks due to amino acids are apparent and the intensity of the $\left(\mathrm{CH}_{2}\right)_{n}$ signal is increased. This is because of a much greater unfolding of the membrane protein. These findings demonstrate that the hydrocarbon chains of the lipid are partially interlocked with a portion of the membrane proteins, and that membrane protein is not in a predominantly random coiled arrangement but is in a highly ordered configuration.

\section{(c) Interaction with sodium deoxycholate and lysolecithin}

In co-dispersions of membrane fragments with sodium deoxycholate or lysolecithin, spectral changes show a concentration dependence which is quite different in each case $\dagger$ (Figs 6 and 7).

Our interpretation of the spectral changes observed with sodium deoxycholate is that the deoxycholate liberates lipid from the protein and then forms a mixed micelle with the liberated lipid. Bile salt and lipids are known to form mixed micelles (Small \& Bourgès, 1966). In these micelles the molecular motion of the deoxycholate proton groupings may be inhibited but molecular motion of the lipid is quite considerable.

The spectrum of the membrane co-dispersed with lysolecithin, however, shows inhibition of the chain signal of lysolecithin (Fig. 7). Our interpretation of the spectral changes observed with lysolecithin is that it forms an additive complex with the membrane material. A complex micelle formation has been reported in the case of myelin lipoprotein solubilized by lysolecithin (Gent, Gregson, Gammack \& Raper, 1964).

This interpretation of the spectral changes produced by deoxycholate and lysolecithin is consistent with the results of unpublished electrophoretic studies of Wessels and co-workers (Central laboratorium t.n.o., Delft, The Netherlands). They observe that the treatment of erythrocyte membrane with bile salt produces a number of separate components, whereas membrane treated with lysolecithin moves as a single entity in the electric field. An analogous situation has also been reported in the case of membranes of Micrococcus lysodeikticus treated with deoxycholate. This treatment permits electrophoretic separation of lipids from membrane proteins (Salton \& Schmitt, 1967). Narrowing of the $\left(\mathrm{CH}_{2}\right)_{n}$ signal and the appearance of the $\mathrm{CH}=\mathrm{CH}$ peak at 4.7 p.p.m. is also obtained in the p.m.r. spectrum of membrane fragments co-dispersed with increasing concentration of sodium lauryl sulphate (unpublished observations). Since bile salts and detergents are reported to weaken hydrophobic bonds (Green \& Tzagoloff, 1966; Meyer \& Kauzmann, 1962) and are more potent than urea in denaturing proteins, these results provide additional evidence of hydrophobic association of hydrocarbon chains with part of the membrane protein.

Our n.m.r. studies of membranes, although still somewhat preliminary, appear promising for the future study of the molecular interaction of drugs and other molecules with cell membranes.

We are grateful to Dr E. Cleghorn, North London Blood Transfusion Centre, Edgware, Middlesex, for a generous supply of human erythrocytes throughout the investigation. We wish to acknowledge the assistance of A. Flook and T. Jenkinson with n.m.r. spectroscopy and D. Mayall with the preparation of the membrane material.

† The same spectral changes are observed with both sonicated and homogenized membranes. 


\section{REFERENCES}

Abell, L. L., Levy, B. B., Brodie, B. B. \& Kendall, F. E. (1952). J. Biol. Chem. 195, 357. Bangham, A. D. (1963). In Advances in Lipid Research, vol. 1, p. 65. New York: Academic Press, Inc.

Borgström, B. (1952). Acta Physiol. Scand. 25, 101.

Bovey, F. A., Tiers, G. V. D. \& Filipovich, J. (1959). J. Polymer Sci. 38, 73.

Chapman, D. (1965). Structure of Lipids. London: Methuen.

Chapman, D., Kamat, V. B., de Gier, J. \& Penkett, S. A. (1967). Nature, 213, 74.

Chapman, D. \& Magnus, P. D. (1966). Introduction to Practical High Resolution Nuclear Magnetic Resonance Spectroscopy. New York: Academic Press, Inc.

Chapman, D. \& Morrison, A. (1966). J. Biol. Chem. 241, 5044.

Chapman, D. \& Penkett, S. A. (1966). Nature, 211, 5055.

Chapmen, D. \& Salsbury, N. J. (1966). Trans. Faraday Soc. 62, 2607.

Cook, G. M. W. (1962). Nature, 195, 159.

Danielli, J. F. \& Davson, H. A. (1935). J. Cell. Comp. Physiol. 5, 495.

van Deenen, L. L. M. \& de Gier, J. (1964). In The Red Blood Cell, ed. by C. Bishop \& D. M. Surgenor, p. 243. New York: Academic Press, Inc.

Dintenfass, L. (1964). Acta Haematol. 32, 299.

Dodge, J. T., Mitchell, C. \& Hanahan, D. J. (1963). Arch. Biochem. Biophys. 100, 119.

Eylar, E. H., Madoff, M. A., Brody, O. V. \& Oncley, J. L. (1962). J. Biol. Chem. 237, 1992.

Gent, W. L. G., Gregson, N. A., Gammack, D. B. \& Raper, J. H. (1964). Nature, 204, 553. de Gier, J., de Haas, G. H. \& van Deenen, L. L. M. (1961). Biochem. J. 81, 33P.

Green, D. E. \& Tzagoloff, A. (1966). J. Lipid Res. 7, 587.

Hippel, P. H. \& Wong, K. Y. (1964). Science, 145, 577.

Kowalsky, A. (1962). J. Biol. Chem. 237, 1807.

Lenard, J. \& Singer, S. J. (1966). Proc. Nat. Acad. Sci., Wash. 56, 1552.

Lowry, O. H., Roberts, N. R., Leiner, K. Y., Wu, M. L. \& Farr, A. L. (1954). J. Biol. Chem. $207,1$.

Lowry, O. H., Rosobrough, N. J., Farr, L. \& Randall, R. J. (1951). J. Biol. Chem. 198, 265.

MacFarlan, M. G. \& Knight, B. C. J. G. (1941). Biochem. J. 35, 884.

Meyer, M. L. \& Kauzmann, W. (1962). Arch. Biochem. Biophys. 99, 348.

Rand, R. P. \& Luzziti, V. (1967). Biophys. .J. 7, 7.

Reed, C. F., Swisher, S. N., Marinetti, G. V. \& Eden, E. G. (1960). J. Lab. Clin. Med. 56, 281.

Rimington, C. (1942). Brit. Med.J. 1, 177.

Robertson, J. D. (1960). Progr. Biophys. Chem. 10, 343.

Roelofsen, B., de Gier, J. \& van Deenen, L. L. M. (1964). J. Cell. Comp. Phys. 63, 233.

Salton, M. R. J. \& Schmitt, M. D. (1967). Biochem. Biophys. Res. Comm. 27, 529.

Saunders, L. (1966). Biochim. biophys. Acta, 125, 70.

Small, D. M. \& Bourgès, M. (1966). Molecular Crystals, 1, 173.

Wallach, D. F. H. \& Kamat, V. B. (1966). J. Cell Biol. 30, 660.

Warren, L. (1959). J. Biol. Chem. 234, 1971.

Watkins, W. M. (1966). Science, 152, 172. 